\title{
MOVIMENTO CARTONERO VISTO SOB UMA CONCEPÇÃO DE LÍNGUA SOCIOINTERACIONISTA: TRAJETOS LATINO- AMERICANOS E AUTORIA NO ENSINO DE ESPANHOL
}

\author{
Movimiento Cartonero Visto Bajo Una Concepción de Lengua \\ Interaccionista: Trayectos Latinoamericanos y Autoría en la \\ Enseñanza de Español
}

\author{
Fernanda Cristina LOPES \\ Universidade Federal do Paraná \\ fernanda.cris.lopes@gmail.com \\ https://orcid.org/0000-0003-4767-5374 \\ Sarah Pimentel Palacio GARCIA \\ Programa de Pós-Graduação em Letras \\ Universidade Federal do Paraná \\ sarahppgarcia@gmail.com \\ https://orcid.org/0000-0002-3078-0517
}

\begin{abstract}
RESUMO: Considerando a importância da defesa do ensino de espanhol em sala de aula, o projeto Formação em Línguas para Fins Acadêmicos (IFA) — que, desde 2019, chama-se Formação em Idiomas para Vida Universitária (FIVU) —, contribui para a formação inicial de docentes em língua espanhola. Este artigo visa analisar a proposta de trabalho com livros cartoneros, levada a cabo em 2017 pelas autoras, professoras em formação e bolsistas do supracitado projeto de extensão, e discutir sua relevância dentro dos horizontes teórico-metodológicos do IFA e do ensino de espanhol. O encaminhamento da atividade priorizou dois momentos: a construção conjunta de compreensões acerca do movimento cartonero, iniciado na Argentina em 2002, e a produção, por parte dos alunos, de livros cartoneros a partir do gênero biografia. Para tanto, este artigo busca analisar partes das unidades, produzidas pelas autoras que ministravam um módulo de espanhol no contexto do projeto em 2017, e possibilitar algumas reflexões acerca da prática docente e a importância da formação inicial de docentes. PALAVRAS-CHAVE: Sociointeracionismo; ELE; Cartonerismo; Extensão universitária.
\end{abstract}

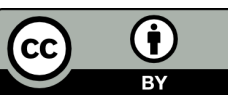


RESUMEN: Desde el reconocimiento de la importancia de defender la enseñanza del español en el aula, el proyecto Formación en Lenguas para Fines Académicos (IFA) — que, desde 2019, se denomina Formación en Idiomas para Vida Universitaria (FIVU) - , contribuye a la formación inicial de profesores de español. Este artículo tiene como objetivo analizar la propuesta de trabajo con libros cartoneros, realizada en 2017 por las autoras, profesoras en formación y becarias en el proyecto de extensión, y discutir su relevancia dentro de los horizontes teóricos y metodológicos del IFA y de la enseñanza de español. El desarrollo de la actividad priorizó dos momentos: la construcción conjunta de entendimientos sobre el movimiento cartonero, iniciado en Argentina en 2002, y la producción, por parte de los estudiantes, de libros cartoneros que mantengan relaciones con el género biografía. Para ello, este artículo busca analizar partes de las unidades, elaboradas por las autoras, que impartieron un módulo de español en el contexto del proyecto en 2017, y permitir algunas reflexiones sobre la práctica docente y la importancia de la formación inicial. PALABRAS CLAVES: Sociointeraccionismo; ELE; Cartonerismo; Extensión universitaria.

\section{CONSIDERAÇÕES INICIAIS}

O projeto de extensão Formação em Idiomas para Vida Universitária (FIVU) é um dos projetos de extensão ofertados no âmbito do curso de licenciatura em Letras da UFPR que colabora com a formação inicial de docentes no ensino-aprendizagem de língua estrangeira moderna (LEM). Sendo atrelado às disciplinas de Metodologia de ensino de LEM e Prática de docência em LEM, que integram o currículo da licenciatura em Letras para as habilitações em LEM, o projeto não apenas possibilita um espaço para a prática docente inicial no ensino de língua estrangeira por meio da participação das (dos) estudantes que cursam as supracitadas disciplinas como também alia reflexões teóricas concernentes ao ensino-aprendizagem. Nesse sentido, esse espaço de formação inicial é construído pelas(os) voluntárias(os), pelas(os) estudantes ${ }^{1}$ de Letras e pela equipe

\footnotetext{
${ }^{1}$ Como forma de adotar uma tentativa de linguagem igualitária de gênero, utilizaremos como primeira opção a flexão no feminino. Levamos em consideração as discussões acerca da linguagem não binária em que se inclui todas as formas de gêneros, é o caso da "@”, do " $X$ " e do "e". No entanto, optamos por incluir os gêneros feminino e masculino. Algumas palavras utilizadas no trabalho e lidas no masculino, como "sujeito", "indivíduo", "ser", "outro", por serem utilizadas em concepções de diferentes autoras(es), manteremos no masculino. Sabemos que a linguagem é uma construção social e que, considerando os limites da linguagem que ainda reflete e refrata discursos de uma tradição dualista, nela devem ser ressignificadas todas as formas e entendimentos de gênero.
} 
de docentes formadores do DTPEN, do Setor de Educação da UFPR, que participam do projeto a partir de uma abordagem metodológica da pesquisa-ação (TRIPP, 2005). Portanto as concepções teóricas (re)elaboradas em sala nas disciplinas de metodologia e práticas, aliadas à prática docente e ao trabalho de investigação ofertados pelas reuniões, seminários e discussões oportunizados pelo projeto, possibilitam a construção de conhecimento com base em um processo ativo de investigação.

Embora o nome do projeto seja, desde 2019, Formação em Idiomas para Vida Universitária, utilizaremos, daqui em diante, o nome Formação em Línguas para Fins Acadêmicos (IFA) ${ }^{2}$, utilizado de 2009 a 2018, pois ele carrega uma historicidade que mantém relações com o período em que fomos professoras-ministrantes no projeto e, também, em que tiveram lugar as propostas de trabalho analisadas neste artigo.

Retomando nossa linha de raciocínio, a construção integrada do conhecimento se dá a partir da interação dos sujeitos participantes do projeto. Por essa razão, o tipo de formação docente proposta pelo IFA é baseado em uma concepção de ensinoaprendizagem em que a interação discursiva é de suma importância para a construção de sentidos. Um dos principais referenciais teóricos que norteia o projeto é o entendimento de língua proposto por Bakhtin e seu círculo. Segundo essa concepção, os sujeitos se colocam no mundo a partir de suas visões de mundo, seu contexto social, político e econômico, e é por meio da linguagem que irão posicionar-se ideologicamente e expressar seus valores ao mundo (VOLÓCHINOV, 2018). Portanto, nesse contexto, o ensino-aprendizagem de LEM propõe-se como um processo dialógico em que os sentidos são construídos a partir do contato entre as diferentes posições axiológicas dos sujeitos em sala de aula.

Assim, a prática docente e a aula de espanhol, quando abordados desde o conjunto de pressupostos do IFA, possibilitam um olhar educacional que reflete e refrata os diferentes discursos presentes na sociedade e que são, por sua vez, irreversivelmente permeados por relações ideológicas. Um projeto de extensão como o IFA, inseparável da comunidade de que faz parte, é colocado em movimento a partir dos objetivos das (os) estudantes dos módulos ofertados: estudantes de graduação e de pós-graduação

\footnotetext{
${ }^{2}$ Como o projeto foi ficando cada vez mais conhecido, os alunos em geral passaram a chamá-lo de Idiomas para Fins Acadêmicos (IFA), já que o nome oficial (FORMAÇÃO EM LÍNGUAS PARA FINS ACADÊMICOS) era muito longo. Esse nome fantasia - IFA - passou a fazer parte da identidade do projeto.
} 
da UFPR que buscam uma formação em $\mathrm{LE}^{3}$, seja porque seus estudos requerem tais conhecimentos, seja para preparar-se para um exame de idiomas, para realizar um intercâmbio ou participar de congressos e eventos internacionais. Nesse sentido, a partir de uma perspectiva bakhtiniana, a língua não se resume a seus aspectos gramaticais, mas se faz a partir de suas dimensões sociais, culturais, políticas e ideológicas: "A língua no processo de sua realização prática não pode ser separada do seu conteúdo ideológico ou cotidiano" (VOLÓCHINOV, 2018, p. 181). Considerando que o contexto político e social dos sujeitos mantém relação com as necessidades da(o) estudante de espanhol dentro de sala, os aspectos sociais que dizem respeito à hispanidade são priorizados no ensino-aprendizagem de espanhol.

Portanto, diante da proposição de nos (re)pensarmos como professoraspraticantes, é premente questionar constituições discursivas sobre a língua que dialoguem com uma "[...] ideologia monolíngue e a hermenêutica monotópica da modernidade e o nacionalismo.” (MIGNOLO, 2003, p. 302, tradução nossa) ${ }^{4}$, de modo que o espanhol possa ser pensado por meio de temporalidades e espacialidades que se inserem no global e no nacional, no regional e no local, relativizando fronteiras e propondo a dissolução de alguns imaginários. Na contracorrente desse horizonte de pensamento, o contexto educacional experienciado pela massiva maioria das(os) alunas(os), ou seja, o latinoamericano, caracteriza-se por uma tradição de ensino-aprendizagem de espanhol que está pautada pelo fomento da padronização da cultura e língua espanholas. A promoção da centralidade do contexto sociocultural e linguístico da Espanha, amplificada a partir de políticas normativas encabeçadas pelo governo espanhol desde a década de 1990 (LAGARES, 2013; DEL VALLE, VILLA, 2005; MORENO CABRERA, 2011; PONTE, 2013), figura uma posição normativa no ensino-aprendizagem de espanhol tanto em instituições de idiomas e na escola básica quanto nos materiais produzidos no contexto

\footnotetext{
${ }^{3}$ O público-alvo do projeto é constituído por 1) estudantes de licenciatura em Letras com habilitação em LEM, cuja função pode ser observar e ministrar as práticas docentes nas aulas dos módulos ofertados, assim como discussões em reuniões, elaboração de materiais didáticos e participação de eventos; 2) alunas(os) de diversos cursos da graduação e pós-graduação da UFPR que buscam aprender uma LEM. A participação dos alunos no projeto é totalmente gratuita. 4 "[...] ideología monolingüe y la hermenéutica monotópica de la modernidad y el nacionalismo." (MIGNOLO, 2003, p. 302).
} 
brasileiro de ensino ${ }^{5}$. Tendo esse reconhecimento em perspectiva, há a preocupação, no interior das discussões e da prática realizada no espaço do IFA, em proporcionar o contato com a diversidade linguística e cultural do espanhol nas aulas.

Ao (re)construirmos um olhar sobre ensino-aprendizagem de LEM tendo essas compreensões como lentes, entendemos que toda enunciação marca uma posição no mundo e, ao mesmo tempo, responde a diferentes outras visões de mundo anteriormente significadas. A linguagem, portanto, nunca poderá ser neutra. Por isso, nós, enquanto investigadoras, também expressamos, a partir deste artigo, nossas perspectivas, que se veem atravessadas por ideologias, valores e visões de mundos de modo inseparável de nosso contexto social, político, cultural e econômico. Assim, buscamos trazer um olhar que reconhece a importância da formação inicial para a nossa prática docente como professoras e investigadoras de língua espanhola (LE).

Em vista disso, este trabalho objetiva, partindo de uma concepção de ensino de língua sociointeracionista, trazer reflexões sobre a proposta, desenvolvida ao longo de 2017, de trabalho com livros cartoneros $^{6}$ e, além disso, discutir sua relevância de acordo com os horizontes teórico-metodológicos do IFA. Para tanto, num momento inicial, partindo de breves considerações sobre o cartonerismo, nos deteremos no processo de construção de unidades temáticas elaboradas por nós em diálogo com nossa orientadora, professora Deise Picanço. Num segundo momento, abordaremos os desdobramentos dessa proposta, que implicou a produção, por parte dos alunos, de livros cartoneros que dialogassem com o gênero biografia.

\footnotetext{
${ }^{5}$ Apesar de haver avanços na produção de LD e no ensino-aprendizagem de línguas voltado para a preocupação de trazer a diversidade linguística e cultural de grupos sociais, proporcionado pelo Programa Nacional do Livro Didático (PNLD) e os Parâmetros Curriculares Nacionais (PCN) no ensino público, algumas pesquisas apontam para a ocorrência de apagamentos da representação cultural de países latino-americanos e da África no ensino-aprendizagem de espanhol em diversos contextos de ensino: isso ocorre em alguns currículos de cursos de Letras Espanhol na graduação (MELLO, 2016) e em LD aprovados pelo PNLD e utilizados na rede básica de ensino (FRAGA, 2016; SANTOS, 2017). Ainda assim, alguns estudos indicam que, na prática e na formação docente, em alguns contextos, haja uma maior discussão acerca da promoção da diversidade linguística e cultural do espanhol, ainda que com limitações (MATOS, 2014; VIEIRA, 2017), assim como na visão das(os) alunas(os) de LE (MOURA SILVA, 2017).

${ }^{6}$ Cartonero: de cartón (papelão).
}

Revista X, v. 16, n. 4, p. 991-1010, 2021. 


\section{Discursos outros na elaboração das unidades temáticas e o contexto das produções cartoneras}

O cartonerismo pode ser descrito como um movimento - contemporâneo, político, editorial, filosófico, cultural - que começou na América do Sul, mais especificamente na região da tríplice fronteira entre Paraguai, Argentina e Brasil. A primeira editora que articulou essa proposta, Eloisa Cartonera, surgiu na Argentina, em 2003, em meio a uma profunda crise econômica vivida por esse país, e nasceu da iniciativa de escritores de criar uma cooperativa com o objetivo de publicar literatura argentina e latino-americana de modo acessível e democrático (RODRIGUES, 2011, p. 26). Seu nome, composto a partir da palavra "cartón", diz respeito ao modo de produção dos livros: com papelões comprados diretamente de catadores (cartoneros, palavra que também nomeia as editoras) e que servem de matéria-prima à capa das edições, confeccionadas à mão. Assim, publicam-se obras, inéditas ou reeditadas, que podem ser de escritores de vanguarda, muitas vezes marginalizados do circuito editorial nacionalglobal, ou de autores que cedem os direitos de publicação ou já estão em domínio público. Desse modo, o objeto livro cartonero é, além de uma partilha comunitária que implica a participação de diversos agentes, uma proposição de novos trajetos da palavra impressa, que (re)traça territorialidades nômades, a despeito de possíveis correspondências cristalizadas entre língua, literatura nacional, território e nação. Prova disso é o paulatino surgimento de outras editoras cartoneras em diversos lugares, como na Colômbia, no Uruguai, na Bolívia e no Peru, (re)configuração que torna possível que um livro como Todo lo que você non sabe es mucho más que todo lo que você sabe (2015), de Douglas Diegues, fosse publicado a um baixo custo simultaneamente por cinco editoras com sedes em distintos países.

Do exposto, como propõe Civallero (2015, p. 10, tradução nossa), a edição de livros cartoneros "[...] redefiniria categorias como autor, livro, publicação e leitor, alteraria a relação entre eles e projetaria novas políticas de autoria, edição, distribuição e uso, com

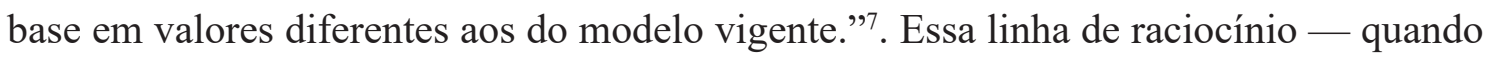
cotejada à perspectiva de que a língua é constituída de distintas vozes sociais, assunção que toma o debate acerca da pluralidade linguística e cultural em sala de aula como eixo axial - , sinaliza que o movimento cartonero e a reflexão sobre o deslocamento contrahegemônico da noção de autoria e língua, que ele possibilita e convoca, podem ser (re)

\footnotetext{
7 “[...] vendría a redefinir categorías como autor, libro, publicación y lector, a alterar la relación entre ellos y a diseñar nuevas políticas de autoría, edición, distribución y utilización, basadas en valores distintos a los del modelo imperante.".
} 
apropriados metodologicamente no ensino de LE. Isso porque, como temos insistido, as línguas são perpassadas por dinâmicas de resistência e hegemonia que mantêm relação com a posição política que uma dada língua assume em determinados contextos. No caso da língua espanhola, Pinto (2011), em diálogo com Mignolo (2003), reconhece um ponto de inflexão referente às dimensões políticas e culturais do fator hegemônico do espanhol a depender do local e do contexto que é situado: "[...] uma mesma língua pode ser tanto objeto de resistência quanto instrumento de resistência. Em cada caso, as relações desiguais entre as línguas precisam ser compreendidas nos contextos em que se articulam com as hegemonias" (MIGNOLO, 2003 apud PINTO, 2011, p. 70). Portanto a posição centralizada do espanhol enquanto "língua oficializada" de alguns países na América Latina pode existir às custas da opressão às línguas indígenas locais, por exemplo; em outros contextos, como no estadunidense, imigrantes latinoamericanos que se expressam em espanhol vivenciam a falta de prestígio de sua língua em detrimento do inglês (PINTO, 2011). Sob essa ótica, observamos que a presença do ensino-aprendizagem de espanhol no currículo básico educacional brasileiro poderia, portanto, contribuir positivamente com o (re)conhecimento, por parte de estudantes e docentes, de grupos marginalizados da/na América Latina. Isso porque a retirada da obrigatoriedade do ensino desse idioma no Brasil, que foi possível a partir do avanço de medidas governamentais que precarizam a oferta do ensino de espanhol e demais línguas na escola básica ${ }^{8}$, atende a demandas de homogeneização — com o inglês como única LE presente na maioria das escolas - que são reflexos da hegemonia neoliberal nos currículos (SZUNDY, 2019).

\footnotetext{
${ }^{8}$ A retirada da obrigatoriedade do componente curricular Língua Estrangeira (LE) à Lei 11.161 da LDB de 1996, a partir da Medida Provisória no 746 de 2016 promulgada pelo governo de Michel Temer, possibilitou a flexibilização do ensino de espanhol, antes obrigatório, nas escolas públicas. A Reforma do Ensino Médio propôs uma nova Base Nacional Comum Curricular que, em 2020, foi adotada em todas as escolas do país e determinou a obrigatoriedade do ensino de inglês desde o $6^{\circ}$ ano do ensino fundamental até o ensino médio, também não contemplando, em seu texto, parâmetros para o ensino das demais línguas estrangeiras na escola.
} 
Nesse sentido, a escolha que guiou este trabalho, desenvolvido no ano de 2017, foi a de elaborar unidades temáticas ${ }^{9}$ que possibilitassem um espaço para o contato com o movimento cartonero e com a escritura de um livro do gênero discursivo biografia a partir do reconhecimento da necessidade de se pensar um ensino-aprendizagem de espanhol permeado pelo local de enunciação de grupos sociais que estão à margem hegemônica. Para tanto, uma prática docente pautada na abordagem sociointeracionista e nas concepções bakhtinianas de linguagem, assim como no desenvolvimento de material didático autônomo ${ }^{10}$, valendo-se de materiais autênticos, favorece a profusão de discursos outros em sala de aula. No contexto do projeto, a partir do enfoque do trabalho com documentos autênticos - isto é, enunciados concretos ${ }^{11}$ e elaborados em uma situação de uso da língua cuja enunciação é ocorrida fora de sala de aula - na elaboração do material e na prática docente, é propiciado um espaço para produções culturais outras.

A palavra "outras", nesse caso, implica o reconhecimento do caráter indissociável entre o "sentido" e o "criar sentido" para Bakhtin. Esse elo incontornável nos (re)coloca

\footnotetext{
${ }^{9}$ As unidades temáticas, para a abordagem sociointeracionista de ensino-aprendizagem de línguas, são desenvolvidas a partir de uma temática que esteja inserida no contexto da(o) aluna(o) e sujeitos na sala de aula. Nesse sentido, segundo Tilio (2013), "Para alcançar o objetivo sociointeracional de efetivamente permitir que o aprendiz atue no mundo usando a língua estrangeira, é fundamental que os conteúdos temáticos propostos propiciem seu engajamento discursivo. Ao oferecer temas familiares, que 'digam algo' ao aluno, e relevantes aos seus contextos situacionais e culturais, cria-se uma oportunidade real para que ele se engaje sociodiscursivamente [...]" (2013, p. 59). Dessa forma, os cursos realizados a partir do projeto Idiomas para Fins Acadêmicos (atualmente intitulado Formação de Idiomas para Vida Universitária) se dividem a partir de unidades elaboradas entorno de uma temática situada no contexto da(o) estudante e participantes do projeto. Assim, uma unidade temática faz parte do material de apoio a uma aula de quatro horas semanais ofertada em um módulo semestral.

${ }^{10} \mathrm{O}$ material didático elaborado pelas participantes foi realizado autonomamente a partir do contexto do projeto de extensão Idiomas para Fins Acadêmicos. Portanto as unidades analisadas neste trabalho formam parte de uma das atividades que contemplavam a formação do(a) participante extensionista assim como uma das avaliações previstas para a disciplina de Teoria e Prática de Ensino de LEM ao final do curso de Licenciatura em Letras LEM. Dessa forma, a partir de discussões proporcionadas no contexto do projeto de extensão sobre a prática pedagógica, aliada a reflexões de textos sobre a abordagem teórico-metodológica sociointeracionista e perspectiva bakhtiniana de língua, as participantes realizaram, de forma conjunta, um material didático próprio e voltado ao contexto universitário da(o) estudante de língua. Nota-se que outros projetos de formação docente de idiomas - como o Centro de Línguas e Interculturalidade (Celin) da UFPR - utilizam livros didáticos produzidos por grandes editoras.

11 "Os autores do Círculo de Bakhtin, em sua discussão sobre a relação entre o verbal e o extraverbal, definem o enunciado concreto como a unidade fundamental da comunicação, composta por duas partes indissociáveis: a parte material ou percebida em palavras, e a parte presumida ou extraverbal. Assim, cada documento autêntico é trabalhado em sua constituição como enunciado concreto, composto por essas duas partes." (PICANÇO; VELOSO, 2019).
}

Revista X, v. 16, n. 4, p. 991-1010, 2021. 
diante de algo que é constantemente (re)construído e (re)constituído, de modo que o enunciado sempre remete a outros enunciados. A essa proposição, corresponde também aquela de que, como sublinha Picanço (2017, não paginado),

[...] a autoria se expressa por meio do conjunto de modos de interlocução compartilhados, compostos por signos e formatados em enunciados verbais e verbovisuais, ideologicamente constituídos. A biografia e a autobiografia, na perspectiva bakhtiniana, constituem gêneros do discurso que, assim como o diário, o romance autobiográfico e a carta, permitem recuperar na narrativa a vida cotidiana e os momentos de resistência e de insurgência do vivido.

A escolha de desenvolver um projeto que tenha como base a escrita de biografias a partir da aproximação do cartonerismo permite a interlocução com discursos outros na sala de aula de LE. A produção de sentido a partir da relação entre eu e outro se dá tanto no interior do entendimento e do desenvolvimento do gênero do discurso elencado quanto nas discussões, em sala de aula, acerca das questões que englobam uma temática, isto é, o movimento cartonero. Portanto é importante ressaltar que as seleções dos temas ao redor dos quais orbitam os gêneros do discurso e os debates produzidos em classe são essenciais para o ensino-aprendizagem de LE no âmbito do projeto IFA. A seguir, iremos explorar com mais atenção o modo como desenvolvemos e elaboramos as unidades temáticas, bem como a escolha do tema e sua relação com os gêneros do discurso abordados em sala para o desenvolvimento do livro cartonero.

\section{REFLEXÕES SOBRE O DESENVOLVIMENTO DE UT E A ELABORAÇÃO DE LIVROS CARTONEROS EM SALA DE AULA}

Como ressaltado anteriormente, no âmbito do projeto IFA, as aulas são desenvolvidas a partir de temas, visto que a elaboração de materiais didáticos dentro desse espaço, fundamentada desde uma perspectiva bakhtiniana de linguagem e com o intuito de uma prática docente alicerçada pela abordagem sociointeracionista, é pensada a partir da prioridade do contexto social e cultural da(o) estudante. Língua e cultura, segundo as concepções de Bakhtin e seu círculo, são intrínsecas, assim como os discursos são atravessados por ideologias. Portanto o programa dos módulos ofertados pelo IFA orbita ao redor de temas que tenham relação com a vida universitária das(os) alunas(os). 
As unidades temáticas (UTs) aqui recuperadas, portanto, estavam inseridas no Curso de Espanhol - Módulo 3/2017'2 (doravante CE-M3/2017), que foi pensado para o trabalho com memória e história, seja no âmbito social, seja no individual. Traremos, nesta seção, algumas reflexões acerca de algumas atividades presentes em UTs elaboradas nesse contexto, cujo desenvolvimento engloba temáticas sobre a infância aliado às atividades baseadas em documentos autênticos, como as biografias de Frida Kahlo e Violeta Parra - audiolivros da Colección Antiprincesas ${ }^{13}$, criada pela editora Chirimbote e distribuída pela editora argentina Editorial Sudestada - assim como o filme Machuca, de Andrés Wood, lançado em 2004.

A partir da discussão do filme Machuca, cuja reprodução contemplou uma atividade extra destinada para casa, buscamos discutir o olhar da infância e a memória histórica em nossas aulas. A produção de Andrés Wood - baseada no romance Tres años para nacer: Historia de un verdadero Machuca (PARRAQUEZ, 2010) — narra os violentos conflitos sociais vividos em Santiago, no Chile, no início da década de 1970, enfocando-se nas últimas semanas do governo de Salvador Allende e na repressão crescente que caracterizou o golpe militar e o início do regime ditatorial de Augusto Pinochet. No centro da narrativa, temos a amizade de três crianças, Pedro, Susana e Gonzalo, que pertencem a diferentes classes sociais. Por meio de discussões acerca do contexto histórico apresentado no filme e de reflexões acerca dos acontecimentos políticos vivenciados no período em que se deram as aulas, resgatamos, em conjunto, a sensibilização às diferenças sociais expostas em Machuca, estabelecendo pontes à experiência social das(os) alunas(os) e participantes. Podemos, nesse sentido, retomar alguns exercícios que procuravam o contato entre o contexto da(o) estudante com o momento histórico retratado no filme:

\footnotetext{
${ }^{12}$ Como na época em que estávamos trabalhando ainda não havia um padrão para denominar os cursos, cada equipe criava um nome e uma sigla, como Espanhol para Fins Acadêmicos (EFA) ou Francês para Fins Acadêmicos (FFA). Essa prática pode ser observada na identificação da Figura 1. ${ }^{13}$ Todos os livros da coleção também estão disponíveis em formato físico, e nossa escolha de trabalhar com os audiolibros se deve à dificuldade de acesso a essas obras no Brasil. Os audiolibros da Colección Antiprincesas são disponibilizados de modo gratuito pela Editora Sudestada na plataforma Soundcloud. Disponível em: https://soundcloud.com/user-631563263. Acesso em: 14 ago. 2020.
}

Revista X, v. 16, n. 4, p. 991-1010, 2021. 
Figura 1: Atividade CE-M3/2017 sobre o filme Machuca, de Andrés Wood.

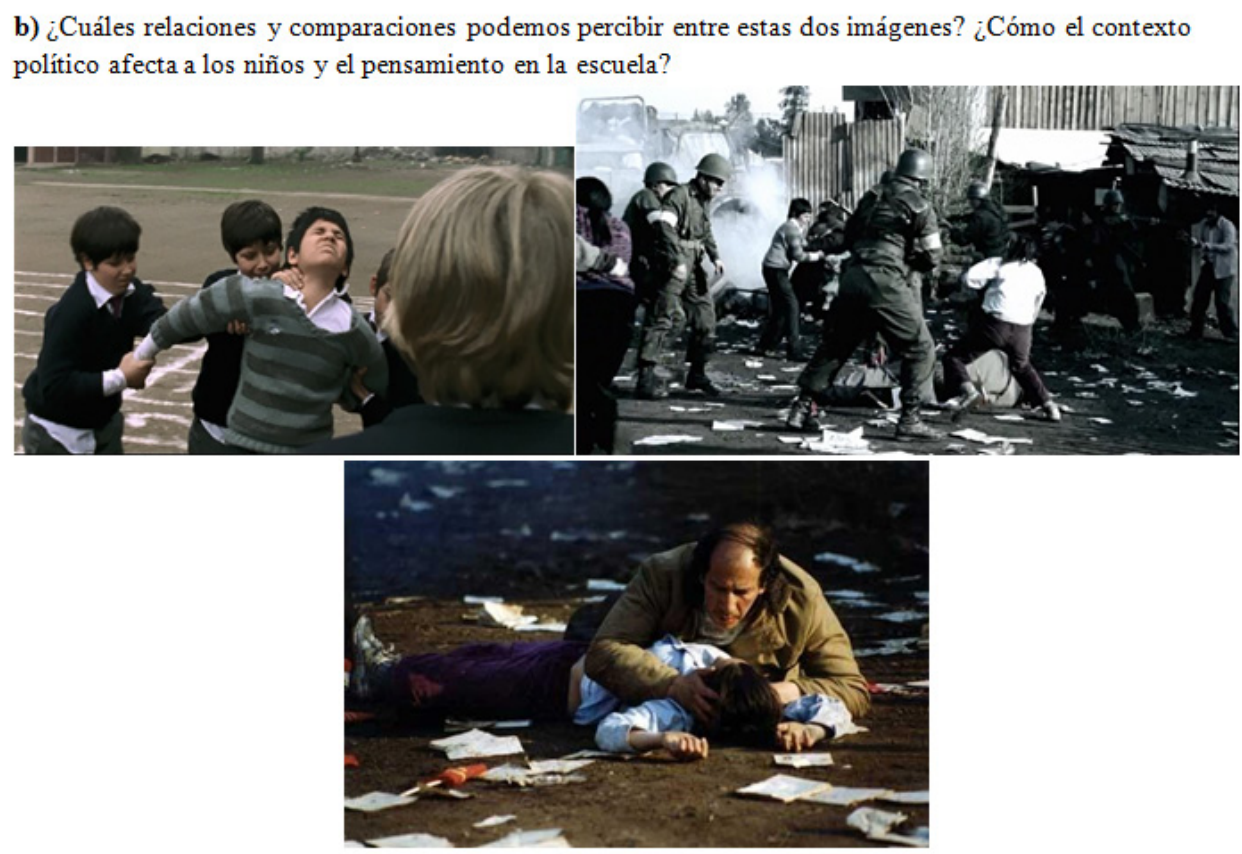

Fonte: MACHUCA. Direção: Andrés Wood. Produção de Andrés Wood Producciones, Tornasol Films, Paraíso Production, Momoun Hassan. Chile: Tornasol Films, S.A., 2004. Filme exibido pela Netflix. Acesso em: 15 jul. 2021.

As atividades das UTs sobre a produção cinematográfica e sobre a supracitada coleção de livros Antiprincesas permitiram a discussão acerca do olhar da infância aos acontecimentos históricos e sociais à medida que as interações em sala de aula proporcionavam momentos de recuperação de vivências da infância das(os) participantes por meio de produções biográficas. É o caso do trabalho com os livros da coleção — a que se somam, posteriormente, Antiheroes como Julio Cortázar e Eduardo Galeano que são, em um primeiro momento, destinados ao público infantil e se propõem a (re) contar as vidas de importantes personalidades latino-americanas, apresentando-as como antiprincesas. Desse modo, como argumentam Morales e Piantoni (2016, p. 271), ao transitar entre o conto e a microbiografia, a coleção

[...] oferece outro olhar, permite que se pense aquilo que "posso" ser. Essa visão propedêutica das "antiprincesas" e "anti-heróis" é um canal de ressignificação, uma ponte entre o mundo e a linguagem dos adultos/as e o das crianças. Esse projeto busca ser disruptivo na forma de propor a discussão sobre os formatos familiares monogâmicos em que filhos e filhas são subordinados aos pais e a mulher ao marido; 
famílias misturadas; o papel das mulheres e a visão sobre gêneros e sexualidades — sim, desse modo, no plural; estereótipos físicos, culturais ou econômicos; destacam também o fim das mulheres como um objeto frágil e fraco que deve ser protegida ou resgatada: são mulheres que tomam as rédeas de suas vidas, apesar das condições em que foram criadas, seu ambiente e mandatos externos; são homens que, longe de ter superpoderes ou de se impor à força, usam a palavra, a fantasia e a utopia para fazer deste mundo um lugar melhor. Os textos que compõem essa proposta promovem o respeito à diversidade, compreendendo e valorizando a especificidade, a particularidade e a singularidade de cada criança, com suas possibilidades e projeções. Esta coleção expõe alguns casos entre milhares e resgata valores de homens e mulheres comuns que decidiram "ser" dentro de um mundo que tenta homogeneizar, que lutaram por ideais e convicções longe do legado patriarcal e religioso que a América Latina herdou de seus conquistadores e que regula a vida das crianças a fim de torná-las "adequadas". ${ }^{14}$

A tentativa de oferecer um olhar à diversidade que busca questionar e confrontar os pressupostos patriarcais que enrijecem os saberes e os seres, como formulam as autoras, parece evocar, desde nosso ponto de vista, nossa preocupação em construir as relações com o outro e suas diferenças no cotidiano das(os) alunas(os) em sala. Nesse sentido, como dito anteriormente, o trabalho com a biografia possibilita ao sujeito a recuperação de sua vivência ao elaborar sua narrativa. Ao retomar as experiências da infância em aula, portanto, a partir da Colección Antiprincesas e Antiheroes, buscamos estabelecer conexões, por meio das UTs e das interações em sala, entre a vivência e memórias da

\footnotetext{
14 “[...] ofrece otra mirada, permite pensar el que "puedo” ser. Esta visión propedéutica de las 'antiprincesas 'y 'antihéroes' son un canal de resignificación, un puente entre el mundo y lenguaje de los adultos/as y el de los niños/as. Este proyecto busca ser disruptivo en la forma de instalar la discusión sobre los formatos de familia de estructura monogámica en la que hijos e hijas están subordinados a sus progenitores, y la mujer al marido; las familias ensambladas; el rol de la mujer y la visión sobre los géneros y las sexualidades, -sí, así, en plural-; los estereotipos físicos, culturales o económicos; ponen de relieve además, el fin de la mujer como un objeto frágil y débil que debe ser protegida o rescatada: son mujeres que toman las riendas de sus vidas a pesar de las condiciones en las que se criaron, de su entorno y los mandatos externos; son hombres que lejos de tener superpoderes o imponerse por la fuerza, utilizan la palabra, la fantasía y la utopía para hacer de este mundo un lugar mejor. Los textos que constituyen esta propuesta promueven el respeto por la diversidad comprendiendo y valorando la especificidad, lo particular y lo único de cada niño y niña con sus posibilidades y proyecciones. Esta colección expone algunos casos entre miles y rescatan valores de hombres y mujeres comunes que decidieron 'ser' dentro de un mundo que intenta homogeneizar, que lucharon por ideales y convicciones lejos del legado patriarcal y religioso que América Latina heredó de sus conquistadores y que regula la vida de niños y niñas con el fin de hacerlos 'encajar'."
}

Revista X, v. 16, n. 4, p. 991-1010, 2021. 
infância das(os) alunas(os) em paralelo com a produção de sentidos a partir desses enunciados e as discussões sobre a situação política, social e cultural latino-americana com o suporte desses textos, como podemos observar a seguir em um segmento dos exercícios de uma das UTs:

Figura 2: Atividade CE-M3/2017 sobre biografias de personalidades hispânicas da Colección Antiprincesas.

4. ¿Leías libros asi cuándo eras niña/ niño? ¿Te acordás de alguno en específico? ¿Te acordás de alguna historia o cuentos que te contaban cuando niño/ niña?

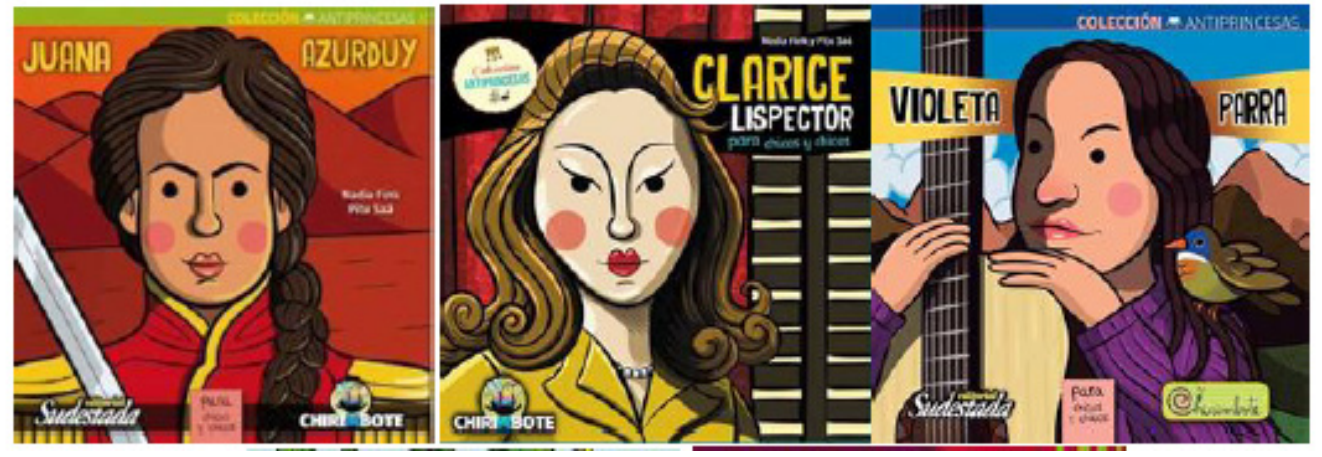

Fonte: SAÁ,P.; FINK, N. Clarice Lispector para chicas y chicos. Ciudad Autónoma de Buenos Aires: Editorial Chirimbote, 2016. (Antiprincesas; 4);SAÁ,P.; FINK, N. Juana Azurduy para chicas y chicos. Ciudad Autónoma de Buenos Aires: Editorial Chirimbote, 2015. (Antiprincesas; 3); SAÁ,P.; FINK, N. Violeta Parra para chicas y chicos. Ciudad Autónoma de Buenos Aires: Editorial Chirimbote y Editorial Sudestada, 2015. (Antiprincesas; 2).

A partir, portanto, dessas leituras, desenvolvemos, em conjunto, atividades que pudessem ampliar o repertório do gênero discursivo biografia e, com isso, desenvolver mais conhecimentos sobre as características desse tipo de enunciado e sistematizar, a partir do uso da língua, os vocabulários e verbos que, atrelados à produção da memória e da temática sobre infância. O trabalho com elementos gramaticais é, assim, construído por meio dos gêneros e do contexto social e cultural dos sujeitos em sala. O processo de desenvolvimento em conjunto dos sentidos dos enunciados, por meio de perguntas, propostos pelas unidades temáticas buscam dar voz ao sujeito a partir da interação discursiva, assim como descentralizar a figura da(o) professor(a) de LE em sala, visto 
que as perguntas realizadas procuram potencializar a autonomia da(o) estudante com relação à compreensão dos documentos (como visto na Figura 2).

A importância da elaboração do contexto dos enunciados é explicitada por meio da construção de relações entre as biografias da Colección Antiprincesas, a análise de diferentes obras publicadas por editoras $\operatorname{cartoneras~}^{15}$, a posterior leitura conjunta de trechos do artigo Ediciones cartoneras latinoamericanas en tiempos de transposición a digital (VILA, 2016) e, finalmente, o trabalho com um vídeo que trata da editora Eloisa Cartonera.

Na UT, diferentes perguntas, formuladas a partir do artigo, procuraram instigar a associação entre essas produções e a atribuição de sentidos (Figuras 3 e 4).

Figura 3: CE-M3/2017, artigo sobre as edições cartoneras.

Español para Fines Académicos $\mid 2$ Módulo III - 2017

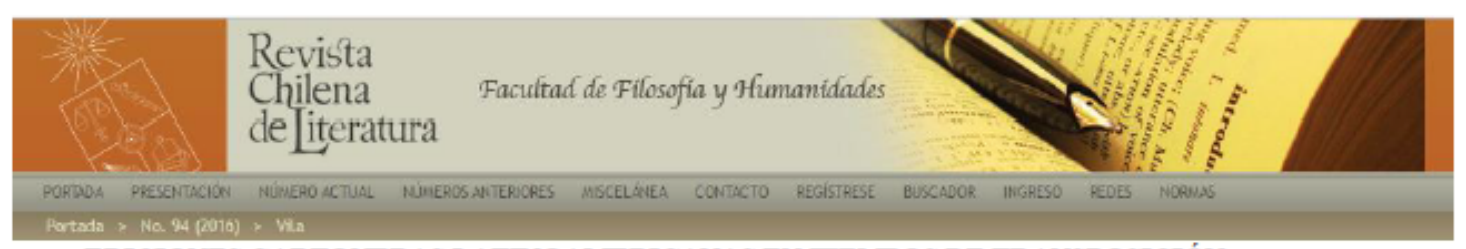

EDICIONES CARTONERAS LATINOAMERICANAS EN TIEMPOS DE TRANSPOSICIÓN

A DIGITAL

Adrián R Vila

Universidad de Buenos Aires; ISFD N` 6 - Chivilcoy; Universidad de Salamanca

editorvila@gmail.com

AHORA BIEN... ¿QUÉ SON LAS EDITORIALES CARTONERAS (EC)?

Fonte: VILA, A.R. Ediciones cartoneras latinoamericanas en tiempos de transposición a digital. Revista chilena de literatura. Diciembre 2016, Número 94, p. 119-143.

\footnotetext{
${ }^{15}$ Depois do trabalho com a Colección antiprincesas y antihéroes, reservamos um momento para que a turma manuseasse livros cartoneros de diferentes editoras e observasse múltiplos aspectos das diferentes publicações (gêneros textuais, autores(as), capa, estrutura, materiais utilizados para a confecção, entre outros).
} 
Figura 4: Atividade sobre a relação entre produção cartonera e Colección Antiprincesas.

Fragmento sacado de: VILA, Adrián R Ediciones cartoneras latinoamericanas en tiempos de transposición a digital. Revista chilena de literatura. Diciembre 2016, Número 94, p. 119-143.

Ahora, junto con un compañero, registren sus reflexiones sobre los siguientes puntos:

11. En el artículo, leemos que: "Asi, las EC se constituyen en plataformas de distribución cultural que reelaboran las formas tradicionales de edición en soporte impreso". ¿Cuáles serian las "formas tradicionales a las que hace referencia? ¿Te parece que la colección antiprincesas formaría parte de este grupo?

Fonte: VILA, A.R. Ediciones cartoneras latinoamericanas en tiempos de transposición a digital. Revista chilena de literatura. Diciembre 2016, Número 94, p. 119-143.

Como já mencionado, após a análise de produções cartoneras e a leitura de um fragmento de um artigo científico que trata do contexto das editoras, uma das perguntas da UT buscou relacionar ambos os tipos de obras. A diferença dos modos de produção dos livros revela os embates entre meios periféricos de conhecimento, ou seja, os livros cartoneros, e o formato tradicional de publicação, este podendo estar atrelado, em alguma medida, à Colección Antiprincesas. Dessa forma, as editoras cartoneras, por seu contexto de produção e origens, estão inseridas em uma posição contra-hegemônica, visto que são meios independentes e periféricos de produção cultural. Nesse sentido, esta discussão é possibilitada pela leitura do artigo de Vila $(2016)^{16}$ e por meio das perguntas que buscam construir essa compreensão a partir da interação entre os sujeitos inseridos na aula de LE.

Na sequência, de acordo com o exposto anteriormente, a UT apresentou um vídeo sobre o processo de edição das obras publicadas pela editora Eloísa Cartonera:

\footnotetext{
${ }^{16} \mathrm{O}$ artigo de Villa propõe uma reflexão sobre a história das editoras cartoneras latino-americanas, sua evolução e relação de seu processo produtivo com a "economia social" no contexto de globalização do mercado editorial.
} 
Figura 5: CE-M3/2017, vídeo sobre confecção de livros cartoneros.

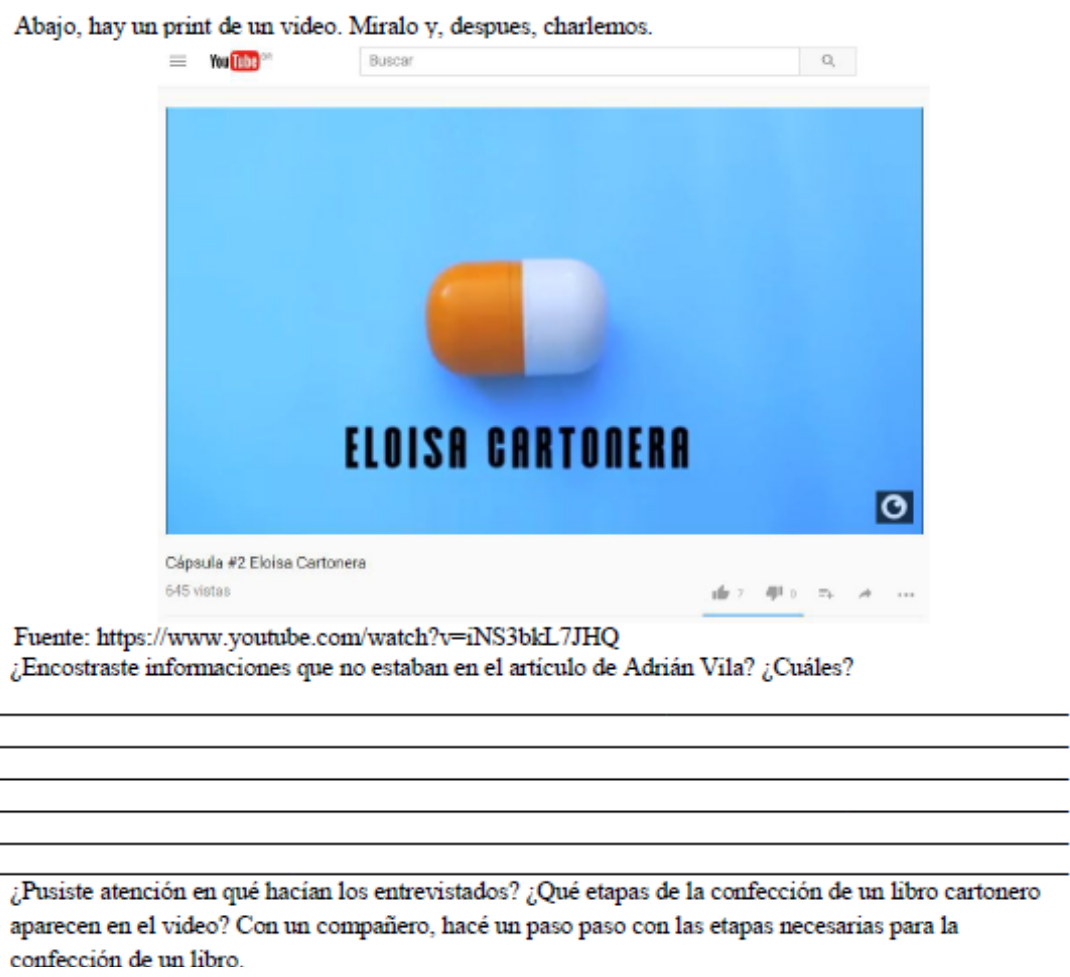

Fonte: COOPERATIVA AUDIOVISUAL, Mil Volando. Cápsula \#2 Eloisa Cartonera. Youtube, 1 dez. 2014. Disponível em: <https://www.youtube.com/watch?v=iNS3bkL7JHQ>. Acesso em: 15 jul. 2021

Através do trabalho de compreensão do vídeo e de associação com a leitura do artigo anteriormente realizada, a pergunta 17 (Figura 5) promove o desenvolvimento das etapas em conjunto com a(o) aluna(o) a partir do que elas(es) puderam compreender, de forma autônoma e conjunta, sobre o enunciado. É por meio de uma pesquisa sobre personalidades hispânicas, realizada pelas(os) estudantes em aula, que se constrói o processo de autoria de um livro cartonero, desde a produção do gênero biografia até a confecção de suas capas personalizadas artesanalmente pelas (os) alunas(os) presentes na aula. A sistematização dos verbos nos tempos passados e do vocabulário necessário para a escrita do texto final foi elaborada no decorrer do desenvolvimento do repertório de leitura dos documentos apresentados ao longo do módulo e colocados em prática na realização do projeto final em sala de aula.

O tempo passado e sua reconstituição - tanto em seu aspecto gramatical quanto no que tange à memória - se tornou o eixo temático no decorrer de todo o Módulo 3 no primeiro semestre de 2017. Construímos sentidos entre a infância e a memória histórica 
a partir das relações discursivas em sala, tanto por meio da interação de alunas(os) e ministrantes quanto por meio dos documentos apresentados pela UT. A elaboração da memória no momento discursivo em sala, materializada em biografias e libros cartoneros, possibilita diálogos com discursos sobre o passado para reconstruir o presente.

\section{Nem todo livro termina com a palavra "fim"}

Escrever sobre uma das nossas primeiras vivências docentes nos faz ressignificar nossa experiência no atual momento. Assim como a produção de narrativas autobiográficas, reelaborar os primeiros trajetos é também permitir um novo olhar aos caminhos docentes do presente. $\mathrm{O}$ olhar em direção à docência se volta para as relações dialógicas, ao contato entre eu e outro assim como entre passado e presente. É a partir da constante reelaboração de sua formação que a(o) professora(or) se insere em sala de aula.

Cabe, portanto, ressaltar que o desenvolvimento do projeto apresentou embates e dificuldades por parte de algumas(uns) alunas(os), já que o processo de produção e de construção de sentidos não é linear nem tampouco livre de conflitos. Como dito anteriormente, a interação discursiva é possibilitada pela heterogeneidade de posições discursivas e, portanto, não é livre de confrontamentos. No entanto, por meio de diálogos, as(os) alunas(os) puderam criar um trabalho em conjunto que potencializou a aprendizagem em espanhol. Nossa produção coletiva, ao fim, possibilitou uma educação transformadora, em que a língua pudesse se desenvolver em seu aspecto social, político e cultural e que contemplasse uma prática descentralizada e autônoma. Como afirmamos em nossa primeira página:

O livro que você tem em mãos nasceu nas aulas do curso Espanhol para Fins Acadêmicos (EFA) e foi desenvolvido pelas alunas do módulo III no primeiro semestre de 2017. O processo de criação dos livros consistiu em pesquisar o contexto de publicação de editoras cartoneras latino-americanas, escrever uma biografia de uma importante figura hispano-americana e criar a capa, cada uma com sua personalidade. Acreditamos que os livros são uma forma de transformar o olhar das pessoas, transmitindo conhecimento para todos e por todos. (IFA, 2017, Acervo Projeto, tradução nossa) ${ }^{17}$

17 "El libro que tenés en manos nació en las clases del curso Español para Fines Académicos (EFA) y fue desarrollado por las alumnas del módulo 3 en el primer semestre de 2017. El proceso de elaboración de los libros consistió en investigar el contexto de las editoriales cartoneras latinomericanas, escribir una biografia de una figura hispanoamericana importante y crear la tapa, cada cual con su personalidad. Creemos que los libros son una manera de transformar la mirada de las personas, transmitiendo conocimiento para todos y por todos. ”.

Revista X, v. 16, n. 4, p. 991-1010, 2021. 
Depois de três anos do desenvolvimento das atividades referentes à proposta de trabalhar o movimento cartonero sob o viés da autoria e das (re)construções de sentido no âmbito do IFA ${ }^{18}$, voltar a elas e, dessa vez, encará-las unicamente como objeto de reflexão, é, de certo modo, vislumbrar um outro. Torna-se inevitável, desse ponto de vista, (re)constituí-las a partir do reconhecimento de que a formação de professores é contínua, não linear e atravessada pelo outro. Em nossas trajetórias docentes posteriores à participação no projeto, entretanto, reafirma-se a importância de defender espaços de discussão e construção de discursos contra-hegemônicos e, no limite, construir sentidos para uma educação que possibilite, segundo um dito zapatista, un mundo donde quepan otros mundos.

\section{REFERÊNCIAS}

CIVALLERO, Edgardo. Libros cartoneros. Olvidos y posibilidades. 2015. Disponível em: https://issuu.com/edgardo-civallero/docs/libros_cartoneros. Acesso em: 14 ago. 2020 .

DEL VALLE, J.; VILLA, L. Lenguas, Naciones y Multinacionales: las políticas de promoción del español en Brasil. Revista da ABRALIN, v. 4, n. 1 e 2, dez. 2005. p. 197230.

DIEGUES, Douglas. Tudo lo que você non sabe es mucho más que todo lo que você sabe. Perú: Cartonazo Editores; México: La Regia Cartonera; España: Ediciones Karakartón; Chile: La Joyita Cartonera; Argentina: Casimiro Bigua Ediciones; Brasil: Vento Norte Cartonero, 2015.

FRAGA, N. G. A (in)visibilidade da América Latina em Enlaces e Eco: manuais de ensino do espanhol como língua estrangeira/ adicional para brasileiros. 2016. $60 \mathrm{f}$. Trabalho de Conclusão Final (Mestrado Profissional em Letras Estrangeiras Modernas) — Universidade Estadual de Londrina, Londrina, 2016.

LAGARES, Xoán Carlos. O espaço político da língua espanhola no mundo. Trabalhos em Linguística Aplicada, Campinas, v. 52, n. 2, p. 385-408, 2013. Disponível em: https://www.scielo.br/scielo.php?pid=S0103-18132013000200009\&script $=$ sci_ abstract\&tlng=pt. Acesso em: 11 de nov. de 2020.

\footnotetext{
${ }^{18}$ Depois da finalização do CE-M3/2017, também propusemos, em outras turmas, no contexto do projeto, o trabalho com as editoras cartoneras e a produção de livros cartoneros. Essas propostas, entretanto, não se relacionaram diretamente ao programa do Módulo 3, caracterizando-se por diferentes estratégias, encaminhamentos e desafios. Atualmente, os livros produzidos pelos alunos durante os anos de 2017 e 2018 fazem parte do acervo do projeto.
} 
MATOS, Doris Cristina Vicente da Silva. Formação intercultural de professores de espanhol: materiais didáticos e contexto sociocultural brasileiro. 2014. 372 f. Tese (Doutorado em Língua e Cultura) - Universidade Federal da Bahia, Instituto de Letras, Salvador, 2014.

MELLO, F. C. de. Se a língua espanhola está presente na América Latina, a América Latina está presente nos currículos de Letras-Português/Espanhol? 2016. Dissertação (Mestrado em Linguística Aplicada). Programa de Pós-graduação em Linguística Aplicada, Universidade do Vale do Rio dos Sinos (UNISINOS). São Leopoldo: UNISINOS, 2016.

MIGNOLO, Walter. Historias locales/diseños globales. Colonialidad, conocimientos subalternos y pensamiento fronterizo. Madri: Ediciones Akal, 2003.

MORALES, María; PIANTONI, Giulietta. Colección antiprincesas + antihéroes. La Aljaba, v. 20, p. 271-274, 2016.

MORENO CABRERA, J. C. Unifica, limpia y fija. La RAE y los mitos del nacionalismo lingüístico español. In: SENZ, Silvia; ALBERTE, Montserrat (ed.). El dardo en la Academia. v. 1. Barcelona: Ed. Melusina, 2011, p. 157-314.

MOURA SILVA, A. C. C. Processos de identificação e (des)identificação nas aulas de Espanhol: problematizando as identidades latino-americanas. 2017. 127 f. Dissertação (Mestrado em Letras e Linguística) — Universidade Federal de Goiás, Goiânia, 2017.

PICANÇO, Deise C. de L. Autoria, produção de texto e editoração de livros artesanais como práticas culturais. In: CICLO DE ESTUDOS DE LINGUAGEM E II CONGRESSO INTERNACIONAL DE ESTUDOS DE LINGUAGEM, 9. 2017. Anais eletrônicos [...]. Campinas: Galoá, 2017. Disponível em: https://proceedings.science/ciel-2017/papers/ autoria--producao-de-texto-e-editoracao-de-livros-artesanais-como-praticas-culturais-. Acesso em: 10 ago. 2020.

PINTO, J. P. Da língua-objeto à práxis linguística: desarticulações e rearticulações contra hegemônicas. Linguagem em foco, v. 2, p. 69-83, 2011.

PONTE, Andrea Silva. General, globalizada, neutra, panhispánica e transnacional: la lengua, muitos nomes, um produto. 2013. Tese (Doutorado em Língua Espanhola e Literaturas Espanhola e Hispano-Americana). Faculdade de Filosofia, Letras e Ciências Humanas, Universidade de São Paulo, São Paulo, 2013.

RODRIGUES, Evandro. Trajeto kartonero. 2011. 167 f. Dissertação (Mestrado em Literatura Brasileira) — Universidade de Santa Catarina, Florianópolis, 2011. 
SANTOS, G. G. As variedades linguístico-culturais da América Latina em um livro didático de espanhol. Revista Mosaico, São José do Rio Preto, v. 16, n. 1, p. 837-868, 2017. Disponível em: http://www.olhodagua.ibilce.unesp.br/index.php/revistamosaico/ article/view/449. Acesso em: 11 nov. 2020.

SZUNDY, P. T. C. A Base Nacional Comum Curricular e a lógica neoliberal: que línguas(gens) são (des)legitimadas? In: GERHARDT, Ana Flávia Lopes Magela; AMORIM, Marcel Alvaro de. (org.). A BNCC e o ensino de línguas e literatura. Campinas: Pontes Editores, 2019. p. 121-151.

TILIO, Rogério. Repensando a abordagem comunicativa: multiletramentos em uma abordagem consciente e conscientizadora. In: ROCHA, C. H.; FRANCO MACIEL, R. (org.). Língua Estrangeira e Formação Cidadã: por entre discursos e práticas. Campinas: Pontes Editores, 2013. p. 51-67.

TRIPP, David. Pesquisa-ação: uma introdução metodológica. Educação e Pesquisa, São Paulo, v. 31, n. 3, p. 443-466, set./dez. 2005.

VIEIRA, Naiara de Paiva. Performatividade, (des)colonialidade e políticas linguísticas: a identidade do professor de espanhol em instituições brasileiras. 2017. 161 f. Dissertação (Mestrado em Letras). Instituto de Ciências Humanas e Sociais, Universidade Federal de Ouro Preto, Mariana, 2017.

VILA, Adrián R. Ediciones cartoneras latinoamericanas en tiempos de transposición a digital. Revista chilena de literatura, 2016, n. 94, p. 119-143.

VOLÓCHINOV, V. Marxismo e Filosofia da Linguagem: Problemas Fundamentais do Método Sociológico na Ciência da Linguagem. São Paulo: Editora 34, 2018.

Recebido em: 14 ago. 2020.

Aceito em: 07 out. 2020. 